Research report

\title{
Cerebral responses and role of the prefrontal cortex in conditioned pain modulation: an fMRI study in healthy subjects
}

\author{
Volodymyr B. Bogdanov $^{\mathrm{a}, \mathrm{b}, *}$, Alessandro Viganò ${ }^{\mathrm{b}, \mathrm{c}}$, Quentin Noirhomme ${ }^{\mathrm{d}, \mathrm{e}}$, \\ Olena V. Bogdanova ${ }^{f}$, Nathalie Guy ${ }^{g}$, Steven Laureys ${ }^{d, e}$, Perry F. Renshaw ${ }^{f}$, \\ Radhouane Dallel $^{\mathrm{g}, 1}$, Christophe Phillips ${ }^{\mathrm{d}, \mathrm{h}, 1}$, Jean Schoenen ${ }^{\mathrm{b}, 1}$ \\ a INRA, Nutrition et Neurobiologie Intégrée and Bordeaux Segalen University, UMR 1286, 146 rue Léo-Saignat, Bordeaux Cedex, 33076, France \\ ${ }^{\mathrm{b}}$ Headache Research Unit, Department of Neurology, CHR Citadelle, University of Liège, Liège, Belgium \\ c SAMILAL-Dept. Anatomy, Histology, Forensic Medicine, Orthopaedics - La Sapienza, University of Rome; Dept. of Neurology and Psychiatry - La Sapienza, \\ University of Rome \\ ${ }^{\mathrm{d}}$ Cyclotron Research Centre, University of Liège, Liège, Belgium \\ e Coma Science Group, Department of Neurology, University and University Hospital of Liège, Liège, Belgium \\ ${ }^{\mathrm{f}}$ University of Utah, Salt Lake City, USA \\ g Clermont Université, Université d'Auvergne, BP 10448, F-63000 Clermont-Ferrand; Inserm, UMR1107, Trigeminal pain and Migraine F-63000 \\ Clermont-Ferrand; $\mathrm{CHU}$, Clermont-Ferrand \\ ${ }^{\mathrm{h}}$ Department of electrical engineering and computer science, University of Liège, Liège, Belgium
}

\section{H I G H L I G H T S}

- The mechanisms underlying conditioned pain modulation are multifaceted.

- During cold, application-specific cerebral activations were found in precuneus and left insula.

- Conditioned suppression of insula test-pain response was related to hypoalgesia.

- The insular changes are predicted by early prefrontal response to cold conditioning.

- Smaller early prefrontal response predicts heterotopic noxious hyperalgesia.

\section{A R T I C L E I N F O}

\section{Article history:}

Received 27 June 2014

Received in revised form 28 October 2014

Accepted 18 November 2014

Available online 25 November 2014

\section{Keywords:}

Brain imaging

Prefrontal cortex

Conditioned pain modulation

\begin{abstract}
A B S T R A C T
The mechanisms underlying conditioned pain modulation (CPM) are multifaceted. We searched for a link between individual differences in prefrontal cortex activity during multi-trial heterotopic noxious cold conditioning and modulation of the cerebral response to phasic heat pain.

In 24 healthy female subjects, we conditioned laser heat stimuli to the left hand by applying alternatively ice-cold or lukewarm compresses to the right foot. We compared pain ratings with cerebral fMRI BOLD responses. We also analyzed the relation between CPM and BOLD changes produced by the heterotopic cold conditioning itself, as well as the impact of anxiety and habituation of cold-pain ratings.

Specific cerebral activation was identified in precuneus and left posterior insula/SII, respectively, during early and sustained phases of cold application. During cold conditioning, laser pain decreased $(n=7)$, increased $(n=10)$ or stayed unchanged $(n=7)$. At the individual level, the psychophysical effect was directly proportional to the cold-induced modulation of the laser-induced BOLD response in left posterior insula/SII. The latter correlated with the BOLD response recorded 80 s earlier during the initial 10 -s phase of cold application in anterior cingulate, orbitofrontal and lateral prefrontal cortices.
\end{abstract}

\footnotetext{
Abbreviations: ACC, anterior cingulate cortex; BOLD, blood oxygenation level-dependent response; fMRI, functional magnetic resonance imaging; FWER, family-wise

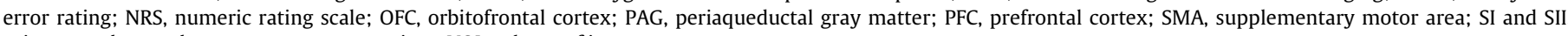
primary and secondary somatosensory cortices; VOI, volume of interest.

* Corresponding author at: Bordeaux Segalen University, 146 rue Léo-Saignat, Bordeaux Cedex 33076, France. Tel.: +33 557571226 ; fax: +33 557571227.

E-mail address: vlabogd@yahoo.com (V.B. Bogdanov).

1 Last authors contributed equally to the supervision of the study.
} 
High anxiety and habituation of cold pain were associated with greater laser heat-induced pain during heterotopic cold stimulation. The habituation was also linked to the early cold-induced orbitofrontal responses.

We conclude that individual differences in conditioned pain modulation are related to different levels of prefrontal cortical activation by the early part of the conditioning stimulus, possibly due to different levels in trait anxiety.

\section{Introduction}

Endogenous pain control is a complex multi-step process composed of several interacting neuronal systems and mechanisms: stimulation-induced analgesia [1], diffuse noxious inhibitory controls [2], ascending nociceptive control [3] and placebo analgesia [4], distraction or disengagement [5,6], stress-induced analgesia [7], and "offset" analgesia [8,9].

Diffuse noxious inhibitory controls (DNIC) are a form of supraspinal endogenous analgesia where phasic test pain responses are attenuated by heterotopic noxious conditioning stimuli.

The term "conditioned pain modulation" (CPM) was proposed to define the psychophysical paradigm to test DNIC [10,11]. In humans, the conditioning stimulus modulating the response to the test stimulus can be painful or non-painful and CPM can inhibit or facilitate this response [11]. CPM can be associated with changes in neuronal activity at multiple sites from spinal cord dorsal horn, medullary nucleus reticularis dorsalis, periaqueductal gray matter [12-14] to prefrontal cortex $[15,16]$

Understanding the mechanisms involved in CPM is important because it is impaired in several hyperalgesic conditions (see for a review [17]: tension-type headache [18], migraine [19,20], fibromyalgia [21,22], irritable bowel syndrome [23], osteoarthritis [24] and chronic post-surgical pain [25].

Functional neuroimaging studies have shown that activations of primary somatosensory (SI), prefrontal (PFC) or anterior cingulate cortices (ACC) are associated with conditioned pain modulation $[15,16,26]$. The PFC, for instance, is activated in healthy controls by heterotopic cold stimulation during rectal pain $[23,27]$. Sustained cold-induced responses in orbitofrontal cortex (OFC) are linked to cold-induced analgesia [15]. Functional coupling between the subgenual anterior cingulate cortex (ACC) and PAG is related to stronger individual heterotopic noxious analgesia [16].

The mechanisms of endogenous analgesia are clearly multifaceted and despite the numerous studies in healthy subjects and in pathological conditions, the precise underlying neural processes are still uncertain. Moreover, pain is a highly subjective experience and can be influenced by differences in individual susceptibility as well as personality. The aim of our study was therefore to search for a link between individual differences in activity of cerebral regions of interest during multi-trial heterotopic noxious conditioning and modulation of the responses to test pain stimuli.

To assess brain activity, we analyzed fMRI BOLD responses phasic laser heat-induced test pain with or without sustained noxious cold conditioning and their correlation with self-ratings of pain levels. We focused on the modulation of test-pain responses in the so-called "pain matrix" [28] and the links between the individual differences in CPM and preceding or concurrent neuronal responses to noxious cold conditioning in prefrontal areas (ACC, lateral PFC and OFC).

Contrary to the above-mentioned studies, we used a repeated block paradigm of noxious cold conditioning alternating with lukewarm application, which allows identifying more precisely responses in PFC to noxious cold stimulation and reduces novelty effects.

We expected that continuous cold pain stimulation would reduce self-ratings of laser heat-induced pain and associated cerebral responses in the pain matrix. In those areas of PFC known from previous studies to be involved in descending analgesia (ACC, lateral PFC and OFC), we searched for cold-induced activation, but also for possible deactivation, as reported in ACC [29] and PFC areas [30]. We hypothesized that individual differences in $\mathrm{PFC}$ responses to cold pain would correlate with levels of CPM.

\section{Material and methods}

\subsection{Subjects}

Twenty-four healthy female volunteers (mean age: 31.3 years, range: 24-45 years) took part in the main experiment and four subjects participated in a pilot study.

None of the subjects was suffering from pain, neurological or psychiatric disorders. All subjects signed an informed consent form that mentioned the general objective, i.e. to study the impact of a cold stimulus on pain and physiological brain responses induced by laser heat stimuli, and were thus naïve about our working hypothesis. They received a financial compensation for travel expenses and time spent in the laboratory. The Ethics Committee of the University of Liège approved the study.

\subsection{Experimental protocol}

Laser heat pulses delivered to the dorsum of the left hand served as painful test stimuli, whereas sustained noxious cold applied on the right foot was used as the conditioning stimulus. Ten blocks of cold stimulation (120 s) alternated with 11 blocks of lukewarm stimulation $(100 \mathrm{~s})$. Single laser stimuli were delivered once $40 \mathrm{~s}$ before the end of each block (Fig. 1).

For the conditioning stimulation, we used an approach similar to that of Sprenger et al., who used 12 small bags ( $600 \mathrm{~g}$ of ice and $250 \mathrm{ml}$ of water) to cover the whole surface of the leg and the foot [16]. We applied two larger bags ( $2 \mathrm{~L}$ of crushed ice and $200 \mathrm{ml}$ of water) to the foot only. There were several bags prepared in advance. They were kept in foam boxes when not applied to the subject. Besides compress bags some additional ice was always present in the container. We controlled the temperature of the ice bags. In general, the temperature in CPM experiments is adjusted by a circulation circuit $\left(5-8^{\circ} \mathrm{C}\right)[31,32]$ or a still ice water bath $\left(4-6^{\circ} \mathrm{C}\right)$ $[15,33]$ such as to be tolerable. In our experiment, the temperature was about $+2{ }^{\circ} \mathrm{C}$ and did not change significantly throughout the experiment. This was achieved by a large proportion of ice in the bags and the storage container, which maintained a low temperature during the melting process. Our mode of cold conditioning resulted in a relatively less powerful noxious stimulation, but all our subjects were able to tolerate repetitive 2 -min noxious cold applications during the entire experimental session.

The same investigator (A.V.) manually applied the compresses over the right foot of the subjects in the scanner room. 


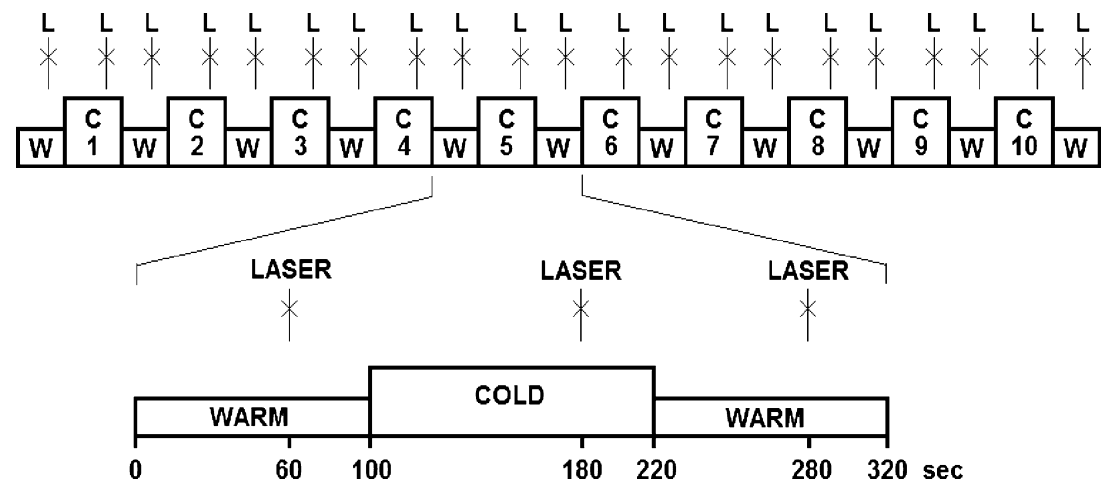

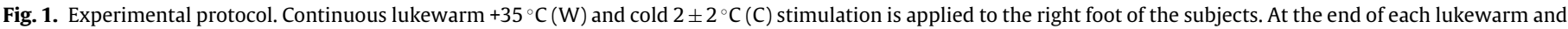
cold block, a single laser pulse (L) is applied to the dorsum of the left hand.

Laser pulses (test pain) were generated by a thulium YAG laser (Baasel Lasertech, Starnberg, Germany) that emits calibrated nearinfrared radiation (wavelength $1.96 \mathrm{~m}$; spot diameter $5 \mathrm{~mm}$; pulse duration $1 \mathrm{~ms}$, energy $600 \mathrm{~mJ}$ ). To familiarize the subjects with the procedure, three laser pulses were administered before the beginning of the experiment. This experiment was realized using Cogent 2000 (Cogent 2000 team and Cogent Graphics developed by John Romaya at the Welcome Department of Imaging Neuroscience).

\subsection{Behavioral data acquisition}

Before the fMRI study, the subjects filled in the French version of Spielberger's trait anxiety inventory [34,35]. They were informed that they should be attentive to the level of pain produced by the heat stimulus on the hand they would have to rate after the experimental session. Pain ratings were performed in pen and pencil format on a numeric rating scale (NRS) from 0 for 'no pain' to 10 for 'worst imaginable pain'. Pain ratings for laser stimuli were obtained separately during lukewarm and cold conditioning. "Behavioral CPM" was defined as a difference of at least one point between laser-pain ratings during cold and lukewarm conditioning.

Subjects rated cold-induced pain for the 1st and the last conditioning, each time at onset and offset of the cold compress application. The average of these four ratings was taken as measure of cold-induced pain. Habituation of cold-induced pain was the difference between ratings during the 1 st and the last application.

\section{4. fMRI data acquisition and analysis}

MRI data were acquired on a $3 \mathrm{~T}$ head-only scanner (Magnetom Allegra, Siemens Medical Solutions, Erlangen, Germany) using the standard transmit-receive quadrature head coil. A structural MRI was obtained in a separate session 20-30 min before the functional acquisition, using a high-resolution T1-weighted image [36]. Multislice $\mathrm{T} 2 *$-weighted functional images were acquired with a gradient-echo echo-planar imaging sequence using an axial slice orientation and covering the whole brain (repetition time $=2040 \mathrm{~ms}$, echo time $=30 \mathrm{~ms}$, flip angle $=90^{\circ}$, field of view $=192 \times 192 \mathrm{~mm}$, voxel size $3 \times 3 \times 3 \mathrm{~mm}$, 34 slices, $25 \%$ interslice gap, matrix size $64 \times 64 \times 34)$. The three initial volumes were discarded to avoid T1 saturation effects. Field map data were also acquired to unwarp the functional images: acquisition time: TR/TE: $517 / 4.92 \& 7.38 \mathrm{~ms}$, flip angle $90^{\circ}$, field of view: $220 \times 220 \mathrm{~mm}^{2}$, resolution: $64 \times 64$, voxel size: $3.4 \times 3.4 \times 3 \mathrm{~mm}$, slices $=32(3 \mathrm{~mm}$ thick, 30\% gap; bandwidth: $260 \mathrm{~Hz} / \mathrm{Px}$ ).

The fMRI images were processed using the "Statistical Parametric Mapping" software (SPM8; Wellcome Trust Centre for Neuroimaging, University College London, UK; http//www.fil.ion. uce.ac.uk/spm) implemented in MATLAB (Mathworks Inc., Sherborn, MA, USA). Functional image time series were corrected for motion and distortion using the "Realign and Unwarp" tool [37] together with the Fieldmap Toolbox [38]. The high-resolution T1 image was co-registered with the functional images and segmented into gray matter, white matter and cerebrospinal fluid [39]. Functional images were spatially normalized to the Montreal Neurological Institute $(\mathrm{MNI})$ space (voxel size: $3 \times 3 \times 3 \mathrm{~mm}$ ) using the normalization parameters obtained from the segmentation procedure and, subsequently, smoothed with a Gaussian kernel with full-width at half-maximum of $6 \mathrm{~mm}$.

\subsection{Statistics}

Data analysis was performed using a general linear model and summary statistics approach.

\subsubsection{BOLD responses to laser-heat stimulation and their modulation by noxious cold}

At the first level, data were subjected to high-pass filtering using a cut-off period of $280 \mathrm{~s}$. Each boxcar or impulse stimulus function was convolved with a canonical hemodynamic response function as implemented in SPM8. Explicit masks were created from the brain mask image available in SPM8. The binary mask was created by thresholding the brain mask image at a level of 0.5 intensity units. This mask fitted the average anatomical image of our subjects' group well.

Preliminary experiments in four subjects with sustained cold/lukewarm stimulation on the foot showed that the onset of both stimulation modalities induced high amplitude but transient BOLD responses with maxima in dorsal SI contralateral to the stimulated side. In order to discriminate this early response, each cold condition was modeled as three successive blocks, lasting $10 \mathrm{~s}$ for "early", $10 \mathrm{~s}$ for "transitional" and $100 \mathrm{~s}$ for "sustained" cold responses. For the sustained lukewarm condition, we only modeled the 1 st $10 \mathrm{~s}$ for "early" lukewarm and the 2 nd $10 \mathrm{~s}$ for "secondary" lukewarm responses. The laser responses were modeled as instantaneous events with separate regressors for those occurring during cold and those occurring during lukewarm stimulation. An autoregressive model of order 1, plus white noise, accounted for correlation of the residuals.

After model estimation, specific effects were tested with appropriate linear contrasts of the parameter estimates, resulting in a contrast value for each voxel. We computed the following contrasts: (1) early non-specific BOLD responses to lukewarm or cold applications; (2) early cold pain responses vs early lukewarm responses; (3) sustained cold responses; (4) laser pain-induced responses during lukewarm condition, as a measure of baseline test pain-induced cerebral changes, (5) cold-induced modulation of laser responses, i.e. change of the laser-induced responses during cold application as compared to those in the lukewarm condition. 


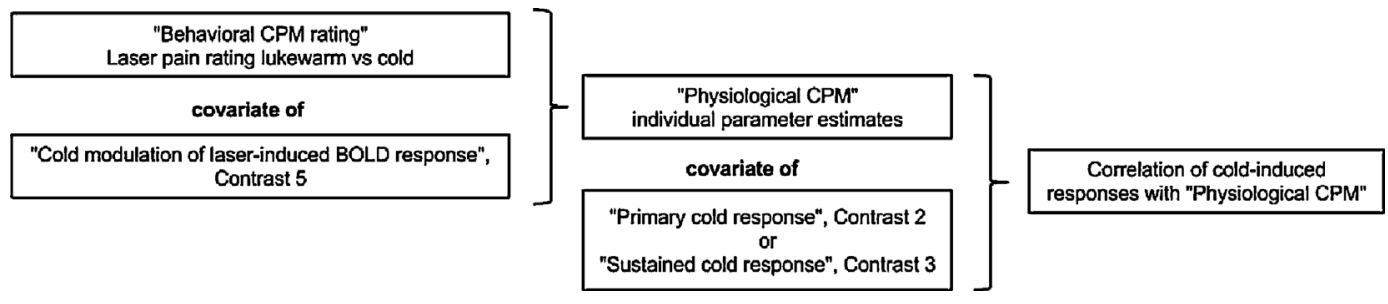

Fig. 2. Sequential outline of the statistical analyses used in the study and definition of terms.

The contrast images were included in a second-level group analysis using a random-effects approach, treating inter-subject variability as a random factor. Group-level effects were tested using one-sided $t$-tests.

\subsubsection{Correlation between behavioral CPM and modulation of laser pain-induced BOLD responses}

The relation between noxious cold conditioning of laser-evoked cerebral responses and behavioral CPM assessed with the NRS was further tested in the second-level group analysis. The modulation of laser responses (contrast 5) and the behavioral analgesia ratings were compared in a between-subject correlation analysis (Fig. 2). This allowed finding brain areas where cold-induced change of the laser pain-induced response was directly correlated with pain ratings, i.e. behavioral CPM. This regional behaviorally correlated modulation of laser-induced neuronal responses was defined as "physiological CPM".

\subsubsection{Correlation between cold-induced responses in prefrontal cortex and physiological CPM}

To verify our hypothesis on the relationship between coldinduced physiological CPM and cold-induced responses in PFC areas, we analyzed the correlation between early, sustained (negative and positive) cold pain responses (contrasts 2 and 3) and physiological CPM (see Fig. 2).

The volume of interest was derived from the statistical map of physiological CPM. Clusters were formed by thresholding the voxel statistics at $p<0.001$ uncorrected. Subsequently, the largest cluster within the "pain matrix" was binarized to create a study-specific mask. This mask covered the areas where physiological CPM was observed. The eigenvariates of individual contrast images of coldinduced modulation of laser responses (contrast 5) were extracted from a brain area outlined with the mask of physiological CPM and used as covariate regressors in further correlation analyses, in particular, in a one-sample $t$-test of individual images of contrasts 2 and 3 (early and sustained cold responses).

\subsubsection{Significance level and directed search for pain responses and pain modulation}

First, we used an undirected search, looking for responses with $p<0.05$ family wise error rate (FWER) corrected for the whole-brain volume both at voxel and cluster levels. For the cluster level inference, we first used a cluster-forming threshold of $p<0.001$ (not corrected). Significant results from this undirected search are indicated in the text and in the tables by ${ }^{*} W B$ (whole brain). Here and in other analyses, we took into account both peak- and cluster-level significance and labeled them as ${ }^{*} \mathrm{WB}$, respectively, next to peak coordinates and cluster size.

Second, we performed a directed search focusing on volumes of interest (VOI). We applied a "small volume correction" in order to obtain FWER-corrected $p$-values at both voxel and cluster levels (with a cluster-forming threshold of $p<0.001$ ). "Pain matrix" VOI included brainstem, thalamus, striatum and cortical areas known to respond to noxious stimulation (see Supplementary Material 1). Significant results for laser and cold responses in "Pain matrix" VOI were labeled with *PM. When a large cluster encompassing multiple brain areas was found, it was masked with the pain matrix to identify specific brain areas included. We defined five bilateral VOI including PFC areas most often reported to be sources of descending CPM effects: medial OFC, lateral OFC, ACC, rostral lateral PFC and caudal lateral PFC (see Supplementary Material 2). Those five masks of PFC VOI were used for cold responses and the correlation analysis of cold responses and physiological CPM. Significant results of this directed search were indicated with ${ }^{*} D S$ (directed search).

Finally, small volume correction was applied to spheres around physiological CPM peaks with a radius of $10 \mathrm{~mm}$ (see Table 2) to test whether the individual ratings of anxiety or across-session cold habituation could influence the above-mentioned responses. Significant results of these analyses were labeled *SV (small volume). Pearson's correlation was estimated for the relation between behavioral and physiological variables.

\section{Results}

\subsection{Behavioral CPM}

Although both laser stimuli and cold application produced pain, the latter was perceived as more painful on the NRS than the former ( $5.6 \pm 0.4$ vs $3.8 \pm 0.3$, respectively, mean \pm SEM) (Fig. 3 ).

We found no significant difference in average ratings of laserinduced pain between the lukewarm and cold conditions, e.g. no significant mean cold-induced behavioral CPM. This was due to the fact that, at the individual level, 7 subjects had hypoalgesia during cold conditioning (NRS reduction of $\geq 1$ ), 10 subjects had hyperalgesia (increase of $\geq 1$ ) and 7 subjects had equal ratings of laser-induced pain during the lukewarm and cold conditions (Fig. 3).

\subsection{Cerebral BOLD responses}

\subsubsection{Non-specific cerebral responses to conditioning stimuli}

Non-specific responses to the application on the right foot of either cold or lukewarm compresses were significant (FWER $p<0.001$ voxel level) in bilateral, but predominantly left, SI, SII, SMA, thalamus, insula, precuneus, ACC, MCC and dorsal premotor cortex, as well as in central cerebellum, midbrain (including PAG), bilateral amygdala, predominantly right hippocampus and dorsolateral PFC.

Less significant activation was also found in caudate nucleus bilaterally, left putamen, frontal operculum and cuneus (FWER $p<0.05$ voxel level) (see Supplementary Material 3).

\subsubsection{Specific cerebral responses to early cold stimulation}

At the whole brain level, when only the response to the first $10 \mathrm{~s}$ of cold stimulation was considered and contrasted to that during the first $10 \mathrm{~s}$ of lukewarm stimulation, we found significant activation in a large cluster including bilateral precuneus, dorsal posterior cingulate and predominantly left occipital cortex (1259 voxels or $34 \mathrm{~cm}^{3}, p<0.005$ FWER cluster level) (Table $1 \mathrm{~A}$ and Fig. 4). In addition, three other significantly large clusters $(p<0.05$ FWER cluster 
A.

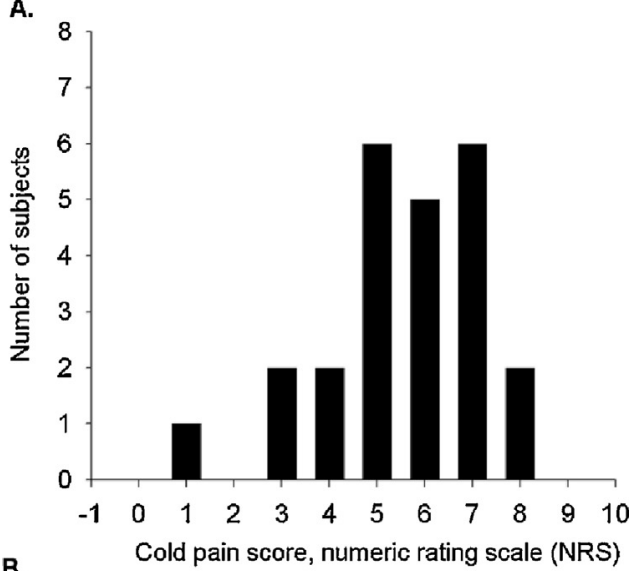

B.

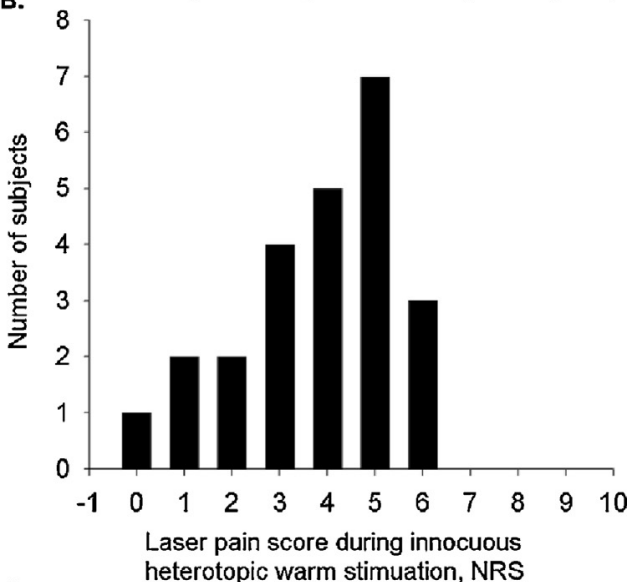

c.

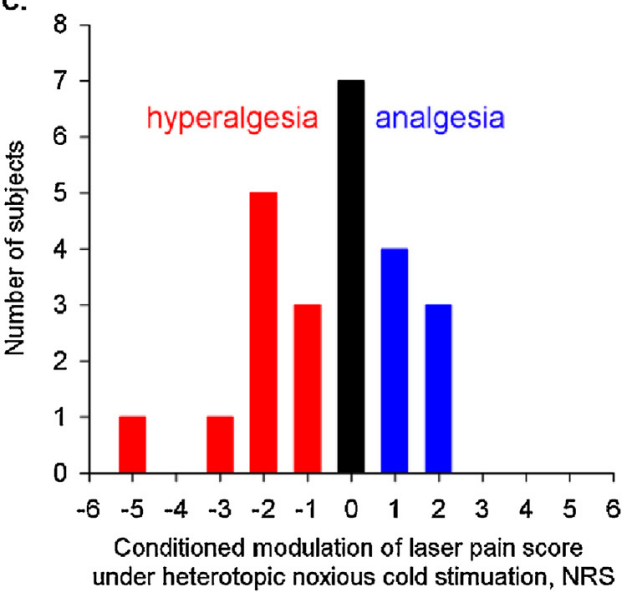

Fig. 3. Distribution of scores on a numeric rating scale (NRS, 0-10) for noxious pain and its modulation by thermal conditioning. The total number of subjects (abscissa) is 24. (A) Cold pain scores. (B) Laser pain scores during lukewarm stimulation. (C) Variation of laser pain scores during noxious cold stimulation expressed as the difference between individual laser pain scores during lukewarm and cold conditioning. Positive values represent cold-induced analgesia while negative values indicate cold-induced hyperalgesia.

level) encompassed left temporo-occipital cortex, right dorsal premotor/motor cortex and right putamen/amygdala.

Using the directed search within VOI of the "pain matrix", the precuneus signal was confirmed to be significant $(p<0.05$ FWER voxel level) and significant clusters were identified in premotor cortex and ventral posterior cingulate (both $p<0.05$ FWER cluster level). In prefrontal VOI, there were three small, but significant clusters in medial OFC and right caudo-lateral PFC (Table 1A and Fig. 4).
Table 1

Brain areas showing a response to noxious stimuli.

\begin{tabular}{|c|c|c|}
\hline & $\begin{array}{l}\text { Cluster size }\left(k_{\mathrm{E}}\right) \\
\text { and cluster level } \\
\text { significance }\end{array}$ & $\begin{array}{l}\text { Peak location } \\
([X, Y, Z] \text { in MNI } \\
\text { coordinates) and } \\
\text { voxel level } \\
\text { significance }\end{array}$ \\
\hline \multicolumn{3}{|c|}{ 1A. Early noxious cold-induced BOLD responses } \\
\hline \multicolumn{2}{|l|}{ Precuneus } & {$[-3-7349]$ *PM } \\
\hline Temporo-occipital cortex & $152 * \mathrm{WB}$ & {$[-57-70-75]$} \\
\hline Dorsal premotor/motor cortex & $124 * \mathrm{WB}(\# 65 * \mathrm{PM})$ & {$\left[\begin{array}{lll}45 & 5 & 58\end{array}\right]$} \\
\hline $\begin{array}{l}\text { Caudal putamen, amygdala, } \\
\text { hippocampus }\end{array}$ & 119 *WB & {$[27-4-8]$} \\
\hline Dorsal posterior cingulate & \#72*WB & {$\left[\begin{array}{lll}6 & -40 & 46\end{array}\right]$} \\
\hline Ventral posterior cingulate & \#68*PM & {$\left[\begin{array}{lll}3 & -43 & 16\end{array}\right]$} \\
\hline \multirow{2}{*}{ Medial OFC } & 7 *DS & {$[1247-11]^{*} \mathrm{DS}$} \\
\hline & $8 * \mathrm{DS}$ & {$\left[\begin{array}{lll}-9 & 29 & -17\end{array}\right]$ *DS } \\
\hline Caudo-lateral PFC & $10 * \mathrm{DS}$ & {$\left[\begin{array}{lll}48 & 23 & 28\end{array}\right]^{*} \mathrm{DS}$} \\
\hline \multicolumn{3}{|c|}{ 1B. Sustained noxious cold-induced BOLD responses } \\
\hline $\begin{array}{l}\text { White matter, caudal corona } \\
\text { radiata }\end{array}$ & $15^{*} \mathrm{WB}$ & {$\left[\begin{array}{lll}-2 & -25 & 25\end{array}\right]^{*} \mathrm{WB}$} \\
\hline \multirow{3}{*}{$\begin{array}{l}\text { Caudate tail and white matter } \\
\text { adjacent to it }\end{array}$} & $5 * \mathrm{WB}$ & {$\left[\begin{array}{lll}18 & -16 & 28\end{array}\right]^{*} \mathrm{WB}$} \\
\hline & $1 * \mathrm{WB}$ & {$\left[\begin{array}{lll}-18 & -1 & 25\end{array}\right]^{*} \mathrm{WB}$} \\
\hline & $1 * \mathrm{WB}$ & {$\left[\begin{array}{lll}-18 & -13 & 28\end{array}\right]^{*} \mathrm{WB}$} \\
\hline $\begin{array}{l}\text { White matter, splenium of } \\
\text { corpus callosum }\end{array}$ & $3 * \mathrm{WB}$ & {$\left[\begin{array}{lll}12 & -37 & 13\end{array}\right]^{*} \mathrm{WB}$} \\
\hline Posterior insula & $4^{*} \mathrm{WB}$ & {$\left[\begin{array}{lll}-33 & -22 & 19\end{array}\right] * \mathrm{WB}$} \\
\hline $\begin{array}{l}\text { Large caudal white matter } \\
\text { cluster }\end{array}$ & $3350 * \mathrm{WB}$ & {$\left[\begin{array}{lll}-21 & -25 & 25\end{array}\right]^{*} \mathrm{WB}$} \\
\hline Rostro-dorsal thalamus & \#102*WB & {$[-12-1919]$} \\
\hline \multicolumn{3}{|c|}{ 1C. Sustained negative noxious cold-induced BOLD response } \\
\hline \multirow[t]{2}{*}{ Medial OFC } & $11^{*} \mathrm{DS}$ & {$\left[\begin{array}{lll}-12 & 29 & -17\end{array}\right]^{*} \mathrm{DS}$} \\
\hline & $7 * \mathrm{DS}$ & [3 $35-17]$ \\
\hline \multicolumn{3}{|c|}{ 1D. Laser pain-induced responses } \\
\hline \multirow[t]{6}{*}{ Insula/frontal operculum } & $514 * W B$ & {$\left[\begin{array}{lll}36 & 17 & -2\end{array}\right]^{*} \mathrm{WB}$} \\
\hline & $79 * W B$ & {$\left[\begin{array}{llll}-30 & 20 & -5\end{array}\right]^{*} \mathrm{WB}$} \\
\hline & $17 * W B$ & {$[45-1616]^{*} \mathrm{WB}$} \\
\hline & $18^{*} \mathrm{WB}$ & {$[-39-7-2]^{*} \mathrm{WB}$} \\
\hline & $2 * W B$ & {$\left[\begin{array}{llll}-30 & 14 & 7\end{array}\right]^{*} \mathrm{WB}$} \\
\hline & $1 * \mathrm{WB}$ & {$\left[\begin{array}{lll}42 & -7 & 10\end{array}\right]^{*} \mathrm{WB}$} \\
\hline Premotor & \#29*WB & {$\left[\begin{array}{llll}48 & 11 & 19\end{array}\right]^{*} \mathrm{WB}$} \\
\hline \multirow[t]{2}{*}{ Amygdala } & \#10*WB & {$[18-4-14]^{*} \mathrm{WB}$} \\
\hline & $\# 4 * \mathrm{WB}$ & {$\left[\begin{array}{lll}-21 & -4 & -14\end{array}\right]^{*} \mathrm{WB}$} \\
\hline ventral putamen & $64^{*} \mathrm{WB}$ & {$\left[\begin{array}{lll}-15 & 8 & -11\end{array}\right]^{*} \mathrm{WB}$} \\
\hline anterior thalamus & $28 * W B$ & {$\left[\begin{array}{lll}9 & 2 & 4\end{array}\right]^{*} \mathrm{WB}$} \\
\hline PCC & $26 * \mathrm{WB}$ & [3 -22 31 $]^{*} \mathrm{WB}$ \\
\hline \multirow{2}{*}{ SII } & $25^{*} \mathrm{WB}$ & {$\left[\begin{array}{lll}-60 & -28 & 22\end{array}\right]^{*} \mathrm{WB}$} \\
\hline & $1 * \mathrm{WB}$ & {$\left[\begin{array}{lll}63 & -22 & 22\end{array}\right]^{*} \mathrm{WB}$} \\
\hline ACC & $19 * \mathrm{WB}$ & {$\left[\begin{array}{lll}0 & 20 & 25\end{array}\right]^{*} \mathrm{WB}$} \\
\hline \multirow{3}{*}{ angular cortex } & $18^{*} \mathrm{WB}$ & {$\left[\begin{array}{lll}-60 & -49 & 43\end{array}\right]^{*} \mathrm{WB}$} \\
\hline & $4^{*} \mathrm{WB}$ & {$[33-4943]^{*} \mathrm{WB}$} \\
\hline & $6 * \mathrm{WB}$ & {$\left[\begin{array}{lll}60 & -40 & 37\end{array}\right]^{*} \mathrm{WB}$} \\
\hline Dorso-lateral PFC & $9 * W B$ & {$\left[\begin{array}{llll}48 & 38 & 7\end{array}\right]^{*} \mathrm{WB}$} \\
\hline \multirow[t]{2}{*}{ Hippocampus } & $2 * W B$ & {$[-15-34-8]^{*} \mathrm{WB}$} \\
\hline & \#48*PM & {$\left[\begin{array}{lll}-18 & -7 & -14\end{array}\right]^{*} \mathrm{WB}$} \\
\hline Caudo-ventral thalamus & $1 * \mathrm{WB}$ & {$\left[\begin{array}{lll}6 & -28 & 4\end{array}\right]^{*} \mathrm{WB}$} \\
\hline Thalamus & $1 * \mathrm{WB}$ & {$\left[\begin{array}{lll}12 & -10 & 10\end{array}\right]^{*} \mathrm{WB}$} \\
\hline SI & $1 * \mathrm{WB}$ & {$\left[\begin{array}{llll}54 & -10 & 16\end{array}\right]^{*} \mathrm{WB}$} \\
\hline OFC & $1 * \mathrm{WB}$ & {$[2729-17]^{*} \mathrm{WB}$} \\
\hline Precuneus & $287^{*} \mathrm{WB}$ & [12 -64 31]*PM \\
\hline \multirow[t]{2}{*}{ Rostro-lateral PFC } & $255^{*} \mathrm{WB}$ & {$\left[\begin{array}{llll}-48 & 38 & 19\end{array}\right]$} \\
\hline & $81^{*} \mathrm{WB}$ & {$\left[\begin{array}{llll}3 & 6 & 53 & 31\end{array}\right]$} \\
\hline SMA & $\# 215^{*} \mathrm{WB}$ & {$\left[\begin{array}{lll}6 & 11 & 61\end{array}\right]^{*} \mathrm{PM}$} \\
\hline midbrain & \#231*WB & {$[0-31-5]^{*} \mathrm{PM}$} \\
\hline Middle temporal gyrus & $60 * \mathrm{WB}$ & {$[-60-587]$} \\
\hline \multirow[t]{2}{*}{ Cerebellum } & $52 * \mathrm{WB}$ & {$[-18-73-32]$} \\
\hline & $57 * W B$ & {$[12-91-26]$} \\
\hline \multirow[t]{2}{*}{ Caudate nucleus } & $\# 8$ & {$\left[\begin{array}{lll}-9 & 8 & 4\end{array}\right]^{*} \mathrm{PM}$} \\
\hline & \#24 & {$\left[\begin{array}{lll}9 & 5 & 7\end{array}\right]^{*} \mathrm{PM}$} \\
\hline
\end{tabular}

Note: WB, whole brain volume corrected undirected search, *PM, "pain matrix" VOI directed search; *DS, directed search at five smaller PFC and ACC VOI. If indicated next to cluster size or next to peak coordinate points at cluster level and voxel level FWER $<0.05$ significance; \#, inclusive anatomical mask was applied to statistical image in order to separate significant response in a small brain area which is a part of a larger cluster. 


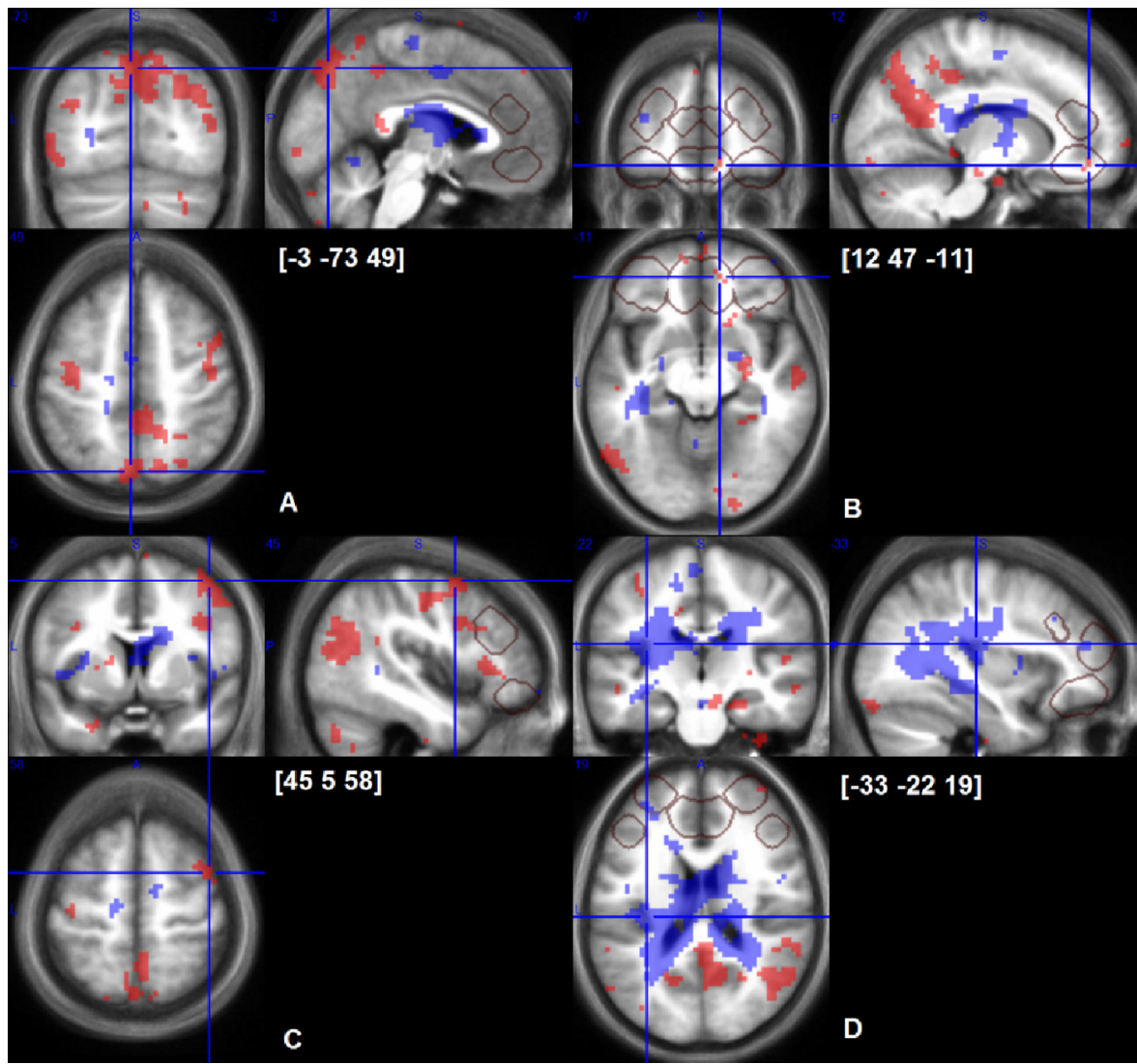

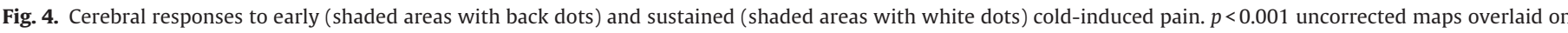

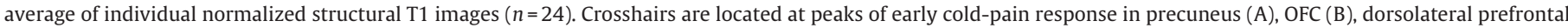
cortex (C) and a peak of sustained cold pain response in posterior insula (D). VOIs of directed search are outlined with grey frames.

\subsubsection{Specific cerebral responses to sustained cold stimulation}

Sustained cold stimulation induced sustained BOLD responses in only a few clusters mostly extending into posterior white matter (Table 1B). Responses were significant in posterior insula and tail of caudate (FWER $<0.05$ voxel level). Those peaks were part of a large significant white matter cluster $\left(30 \mathrm{~cm}^{3}, p<0.001\right.$ FWER cluster level) (Fig. 4). When masking with the "pain matrix" VOI was applied, this $30-\mathrm{cm}^{3}$ cluster included a significant large cluster in rostro-dorsal thalamus ( $p<0.01$ FWER cluster level) (Table 1B). None of the directed searches in prefrontal cortex VOI yielded significant sustained positive responses to cold stimulation, but negative sustained cold responses were disclosed in mOFC VOI (Table $1 \mathrm{C}$ and Fig. 5).

\subsubsection{Laser-induced cerebral responses during lukewarm stimulation}

Laser heat stimuli induced a significant response in most areas of the "pain matrix" mask (see Supplementary Material 1): insula, premotor cortex, amygdala, ventral putamen, anterior thalamus, PCC, SII, ACC, and dorso-lateral PFC (peak level FWER $p<0.005$ ) (Table 1D). Outside of the "pain matrix", there were significant laser-induced responses bilaterally in angular gyrus and cerebellum.

\subsubsection{Changes in laser-induced cerebral responses during cold stimulation}

The overall difference in responses to laser stimuli with or without continuous cold application (contrast 5) was not significant, which was due to the contrasting CPM effect between subjects. Individual differences in cold-induced behavioral CPM scores were in fact proportional to the cold-induced change in laser-induced responses in the right anterior insular cluster partially including white matter, ventral premotor cortex and dorsal striatum. A similar relationship was found in another cluster comprising mostly

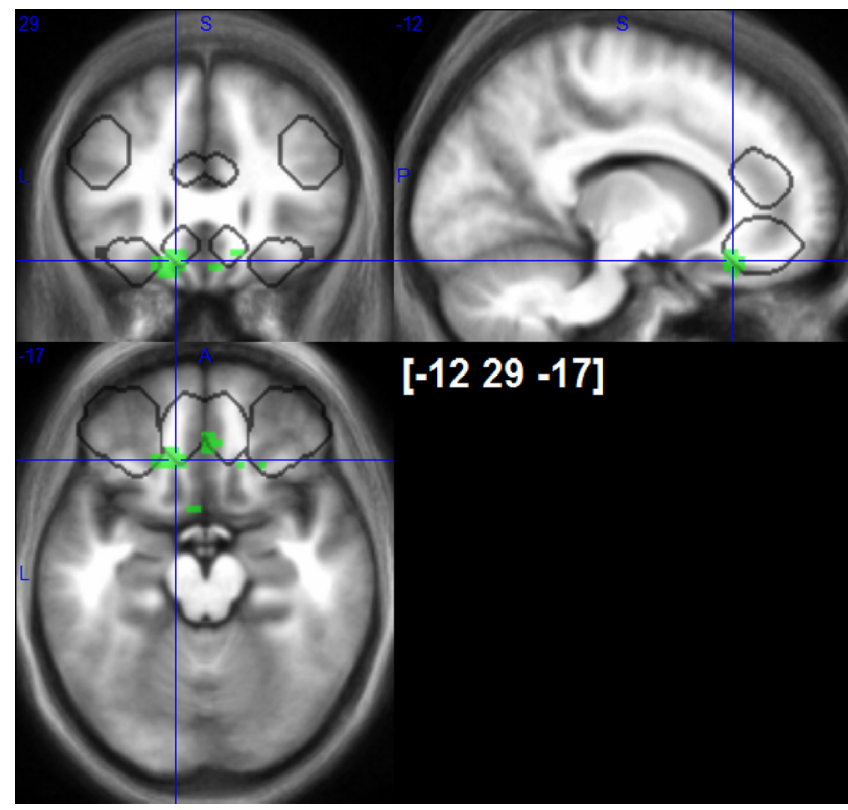

Fig. 5. Negative responses to sustained noxious cold stimulation in medial OFC (outlined with white). Suprathreshod $p<0.001$ uncorrected T-maps. VOIs of directed search are outlined in grey. 
Table 2

Physiological CPM: Cold modulation of laser-induced responses correlated with behavioral CPM.

\begin{tabular}{lll}
\hline & $\begin{array}{l}\text { Cluster size }\left(k_{\mathrm{E}}\right) \\
\text { and cluster level } \\
\text { significance }\end{array}$ & $\begin{array}{l}\text { Peak location } \\
([X, Y, Z] \text { in MNI } \\
\text { coordinates }) \text { and } \\
\text { voxel level } \\
\text { significance }\end{array}$ \\
\hline $\begin{array}{l}\text { Anterior insula/white } \\
\text { matter/premotor } \\
\text { cortex }\end{array}$ & $122^{*} \mathrm{WB}$ & {$[302616]^{* \mathrm{WB}}$} \\
$\begin{array}{l}\text { Posterior insula/SII } \\
\text { Lateral OFC }\end{array}$ & $90^{* *} \mathrm{WB}$ & \\
$\begin{array}{l}\text { Fusiform } \\
\text { gyrus/parahippocampal } \\
\text { Posterior insula/SII }\end{array}$ & $64 * \mathrm{WB}$ & {$\left[\begin{array}{lll}36-16 & 19]^{*} \mathrm{WB} \\
{[24} & 14-20] \\
{[-21-52-11]}\end{array}\right.$} \\
\hline
\end{tabular}

Note: see Table 1.

gray matter within the anatomically defined "pain matrix" mask: left posterior insula and SII. There were two other significant but smaller clusters in lateral OFC and fusiform gyrus/parahippocampal cortex (Table 2). However, when we applied small volume corrections to the "pain matrix" VOI, only the left posterior insula/SII cluster survived directed search (Table 2 and Fig. 6).

We used therefore the insula/SII cluster in the "pain matrix" (cluster size $=58$ voxels) to extract the eigenvariates of cold-induced modulation of laser responses (contrast 5). The cold-induced change of laser-induced responses in this cluster was directly correlated with individual behavioral CPM ratings. As mentioned, we called "physiological CPM" this concordant behavioral-BOLD response modulation (Fig. 2).

\subsubsection{Correlation with specific cold-induced prefrontal cortex responses}

The physiological CPM parameter was used as a covariate regressor in a one-sample $t$-test of individual images of contrasts 2 and 3 (early and sustained cold responses). This tested the hypothesis that a specific pattern of cold-induced responses in PFC preceeds subsequent physiological CPM and hence may explain the individual differences in CPM (see Fig. 2 for the analysis flow). When behavioral CPM ratings were included as a covariate, we obtained similar

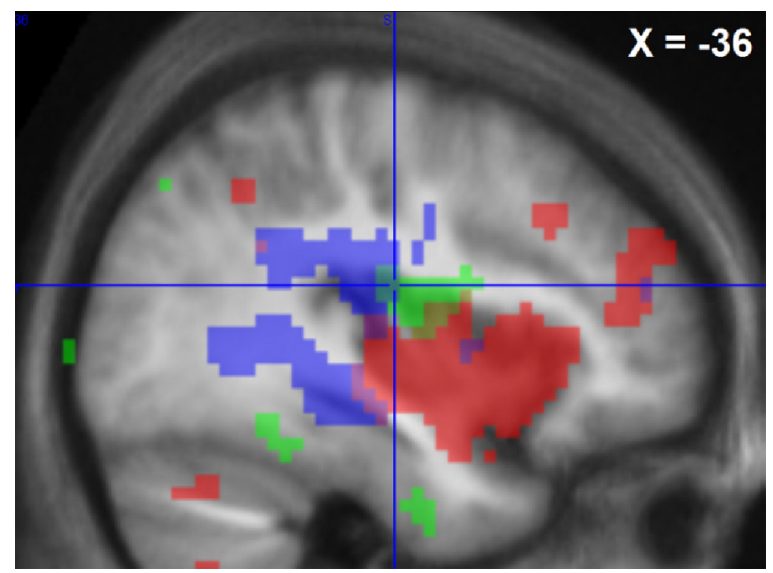

Fig. 6. Cerebral areas that were activated by the Laser-test stimulation during lukewarm, i.e. control, conditioning (shaded area with black dots) or sustained cold conditioning (shaded area with light-grey dots) and areas where cold-induced inhibition of laser responses covariated with individual analgesia ratings ("physiological analgesia", outlined in white). $p<0.001$ uncorrected maps are shown on a sagittal section of average of individual normalized structural T1 images $(n=24)$ at $X=-36 \mathrm{~mm}$ MNI. Crosshair location is at the maximum of green contrast ([ $-36-16$ 19] *PM).
Table 3

Brain areas where cold-induced BOLD responses co-variate with physiological CPM (source of the physiological CPM covariate in left insula/SII).

\begin{tabular}{|c|c|c|}
\hline & $\begin{array}{l}\text { Cluster size and } \\
\text { cluster level } \\
\text { significance }\end{array}$ & $\begin{array}{l}\text { Peak location } \\
([X, Y, Z] \text { in MNI } \\
\text { coordinates) } \\
\text { and voxel level } \\
\text { significance }\end{array}$ \\
\hline \multicolumn{3}{|c|}{ 3A. Early cold-induced BOLD responses related to physiological CPM } \\
\hline \multirow[t]{2}{*}{ Dorso-lateral PFC } & $29 * W B$ & {$\left[\begin{array}{lll}-15 & 50 & 25\end{array}\right]^{*} \mathrm{WB}$} \\
\hline & $4 * W B$ & {$\left[\begin{array}{llll}-2 & 2 & 25 & 31\end{array}\right]$ *WB } \\
\hline \multirow[t]{2}{*}{ Rostral ACC } & $18 *$ WB & {$[94410]$ *WB } \\
\hline & $3 * W B$ & {$\left[\begin{array}{lll}-9 & 41 & 16\end{array}\right]^{*} \mathrm{WB}$} \\
\hline Caudal ACC & $12 * \mathrm{WB}$ & {$\left[\begin{array}{lll}-12 & 29 & 31\end{array}\right]^{*} \mathrm{WB}$} \\
\hline $\begin{array}{l}\text { Anterior-lateral lingual/medial } \\
\text { fusiform gyrus }\end{array}$ & $11 * \mathrm{WB}$ & {$\left[\begin{array}{lll}-24 & -55 & -2\end{array}\right] * \mathrm{WB}$} \\
\hline Medial PFC & $8 * W B$ & [6 55616 16 *WB \\
\hline $\begin{array}{l}\text { White matter, caudal corpus } \\
\text { callosum }\end{array}$ & $8 * W B$ & {$\left[\begin{array}{lll}-15 & -13 & 31\end{array}\right]$ *WB } \\
\hline Caudate head & $7 *$ WB & {$\left[\begin{array}{lll}-15 & 20 & 1\end{array}\right]$ *WB } \\
\hline White matter precentral gyrus & 4 *WB & {$\left[\begin{array}{lll}-36 & -7 & 28\end{array}{ }^{*} \mathrm{WB}\right.$} \\
\hline \multirow[t]{3}{*}{ Caudo-lateral OFC/rostral insula } & $3 * W B$ & {$\left[\begin{array}{lll}-27 & 23 & -14\end{array}\right] * \mathrm{WB}$} \\
\hline & $1 *$ WB & {$\left[\begin{array}{lll}-30 & 29 & -11\end{array}\right]^{*} \mathrm{WB}$} \\
\hline & $1 * \mathrm{WB}$ & {$\left[\begin{array}{llll}-2 & 11 & -17\end{array}\right] \mathrm{WB}$} \\
\hline Ventral striatum/accumbens & $2 * W B$ & {$[68-14]$ *WB } \\
\hline Subgenual ACC & $2 * W B$ & 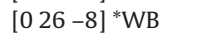 \\
\hline \multirow[t]{2}{*}{ Putamen } & $2 * W B$ & {$\left[\begin{array}{lll}21 & 11 & -8\end{array}\right]$ *WB } \\
\hline & $1 * \mathrm{WB}$ & {$\left[\begin{array}{lll}27 & 5 & 10\end{array}\right]^{*} \mathrm{WB}$} \\
\hline \multirow[t]{2}{*}{ Frontal pole } & 1 *WB & {$\left[\begin{array}{lll}18 & 65 & 13\end{array}\right]$ *WB } \\
\hline & $1 * \mathrm{WB}$ & {$\left[\begin{array}{llll}-2 & 59 & 10\end{array}{ }^{*} \mathrm{WB}\right.$} \\
\hline ACC & $223^{*} \mathrm{DS}$ & {$[94410]$ *DS } \\
\hline Rostro-lateral PFC & $178 * \mathrm{DS}$ & {$\left[\begin{array}{llll}-15 & 53 & 22\end{array}\right]^{*} \mathrm{DS}$} \\
\hline \multirow[t]{2}{*}{ Medial OFC } & $68 * \mathrm{DS}$ & {$\left[\begin{array}{lll}6 & 35 & -2\end{array}\right]$ *DS } \\
\hline & $11 * \mathrm{DS}$ & {$\left[\begin{array}{lll}-9 & 44 & -8\end{array}\right]^{*} \mathrm{DS}$} \\
\hline Caudo-lateral PFC & $26 * \mathrm{DS}$ & {$\left[\begin{array}{lll}45 & 20 & 22\end{array}\right]^{*} \mathrm{DS}$} \\
\hline \multirow[t]{2}{*}{ Lateral OFC } & $20 * \mathrm{DS}$ & {$\left[\begin{array}{llll}-30 & 29 & -11\end{array}\right]^{*} \mathrm{DS}$} \\
\hline & 4 & [39 29 -17] *DS \\
\hline
\end{tabular}

\begin{tabular}{|c|c|c|}
\hline $\begin{array}{l}\text { White matter, internal capsula, } \\
\text { corona radiata, putamen, insula }\end{array}$ & $172 *$ WB & {$\left[\begin{array}{lll}-18 & 11 & 4\end{array}\right]$} \\
\hline Cerebellum & $146 *$ WB & {$[33-58-38]$} \\
\hline $\begin{array}{l}\text { White matter anterior corona } \\
\text { radiata, adjacent to rostro-lateral } \\
\text { PFC }\end{array}$ & $117 *$ WB & [24 38 16] \\
\hline Rostro-lateral PFC & 17 *DS & {$\left[\begin{array}{lll}27 & 47 & 10\end{array}\right]$} \\
\hline \multicolumn{3}{|c|}{$\begin{array}{l}\text { 3C. Negative sustained cold-induced BOLD responses related to } \\
\text { physiological CPM }\end{array}$} \\
\hline $\begin{array}{l}\text { Lateral OFC, white matter corona } \\
\text { radiata, insula, ACC, rostro-lateral } \\
\text { PFC }\end{array}$ & $229 *$ WB & {$\left[\begin{array}{lll}-30 & 23 & -17\end{array}\right]$} \\
\hline \multirow[t]{3}{*}{ Cerebellum } & $83^{*} \mathrm{WB}$ & {$[21-64-41]$} \\
\hline & $64 * \mathrm{WB}$ & {$[36-73-75]$} \\
\hline & $73 * W B$ & {$[-27-64-41]$} \\
\hline Rostro-lateral PFC & $41 * \mathrm{DS}$ & {$\left[\begin{array}{llll}-24 & 47 & 16\end{array}{ }^{*} \mathrm{DS}\right.$} \\
\hline Lateral OFC & $24 * \mathrm{DS}$ & {$\left[\begin{array}{llll}-30 & 23 & -17\end{array}\right]$ *DS } \\
\hline \multirow[t]{2}{*}{$\mathrm{ACC}$} & $8 * \mathrm{DS}$ & {$\left[\begin{array}{llll}-12 & 29 & 19\end{array}\right]^{*} \mathrm{DS}$} \\
\hline & $5 *$ DS & {$\left[\begin{array}{lll}-12 & 44 & 22\end{array}\right]$} \\
\hline Caudo-lateral PFC & $23 *$ DS & [45 35 16 $]^{*} \mathrm{DS}$ \\
\hline
\end{tabular}

Note: see Table 1.

though less significant results that are not presented because we consider them redundant.

Early cold responses in dorsolateral and medial PFC, ACC, lingual/fusiform gyrus, white matter at precentral gyrus and caudal corpus callosum, caudo-lateral OFC/rostral insula, striatum and frontal pole were directly correlated with physiological CPM (FWER $p<0.05$ voxel level) (Table 2A and Fig. 7). We also observed a large $\left(64 \mathrm{~cm}^{3}\right)$ significant cluster (FWER $p<0.05$ cluster level) that included perigenual ACC, rostral bilateral ACC, left lateral OFC, frontal operculum, DLPFC, posterior ACC and head of caudate as well as right dorso-medial PFC and frontal pole (Table $3 \mathrm{~A}$ and Fig. 7).

The directed search within five VOI indicated that physiological $C P M$ was significantly predicted by early cold-induced responses 


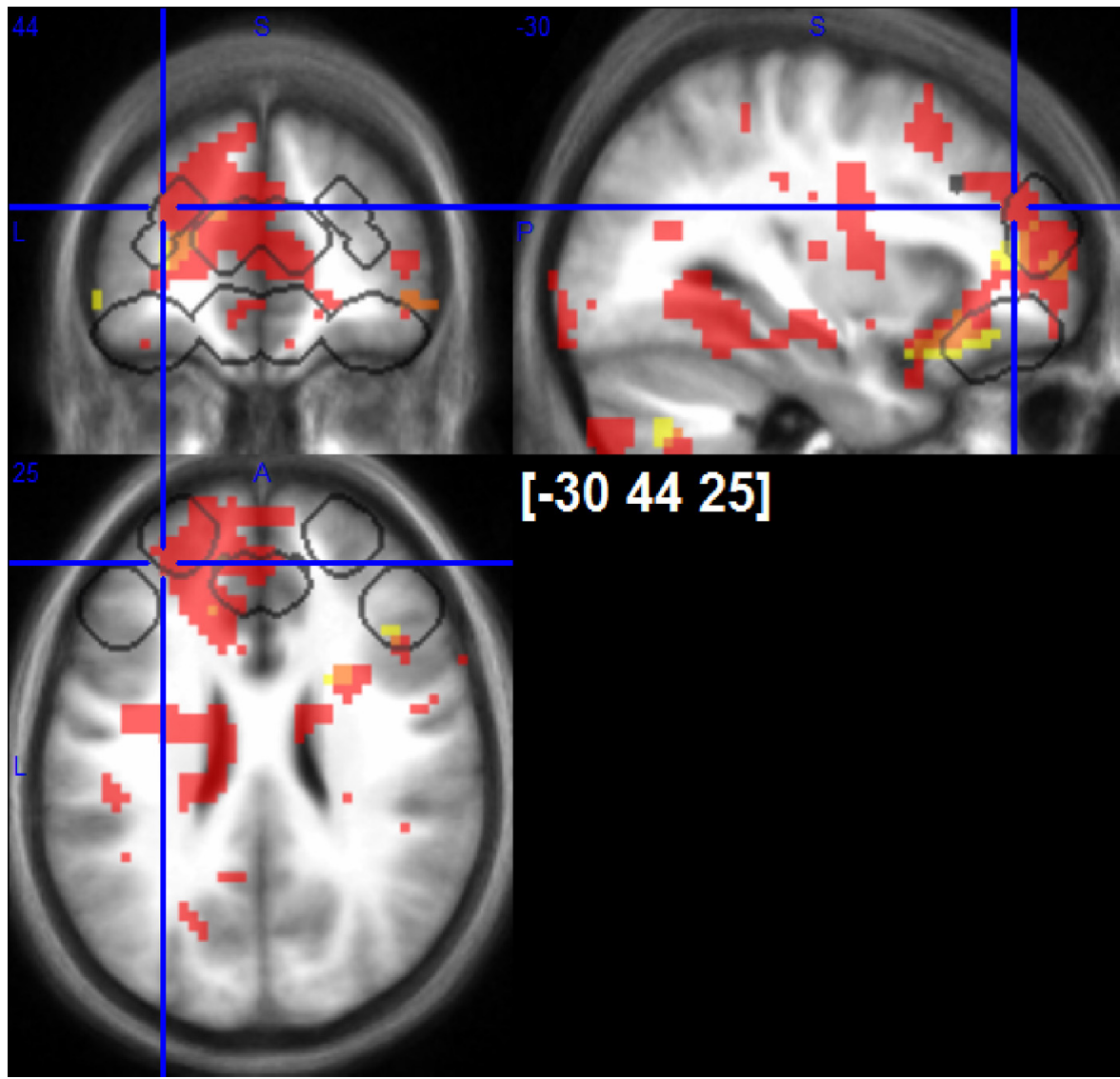

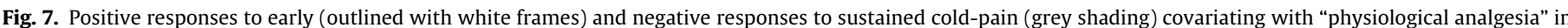

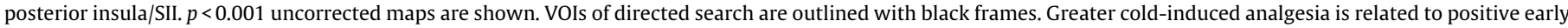
or negative sustained cold-pain responses in ACC, OFC and rostro-lateral PFC.

in all five VOI (medial and lateral OFC, ACC, left rostral and right caudal lateral PFC) (Table $3 \mathrm{~A}$ ).

As illustrated in Fig. 8 for medial subgenual ACC, rostral ACC and lateral OFC voxels, BOLD responses were positive during the early phase of cold conditioning in subjects who became hypoalgesic and had reduced laser-induced activation in left posterior insula/SII, but negative (or less positive) in those who developed hyperalgesia. In those areas there was a clear positive correlation between the hemodynamic responses and physiological CPM, as shown in Fig. 9 for the subgenual ACC VOI.

The correlation between the cerebral responses during sustained cold conditioning and physiological CPM were more complex and variable between areas. Activation during sustained cold conditioning was positively related to physiological CPM in a few areas including cerebellum, corona radiata, internal capsula, dorsal putamen and insula, and a white matter cluster comprising anterior corona radiata and adjacent rostro-lateral PFC. (FWER $p<0.05$ cluster level). The directed search confirmed a single significant cluster (FWER $p<0.05$ cluster level) in right rostro-lateral PFC VOI (Table 3B).

By contrast, there was a negative correlation of sustained cold-induced brain activity with physiological CPM in most of the prefrontal VOI (Table 3C). With the directed search, deactivation was significantly related to hypoalgesia during cold conditioning in lateral OFC, ACC, left rostro-lateral and right caudo-lateral PFC (Table $3 C$ ). At the whole brain level, there was a significant cluster $\left(6 \mathrm{~cm}^{3}\right.$, FWER $p<0.05$ cluster level $)$ including lateral OFC, white matter and dorsolateral PFC (see Fig. 7), as well as three significant clusters in cerebellum.

\subsection{Correlations with anxiety and habituation}

The mean (trait) anxiety score in our subjects was $36 \pm 1$, range 26-51. Greater trait anxiety scores correlated overall with behavioral hyperalgesia during CPM $(r=-0.46, p<0.05)$.

According to the retrospective pain rating, there was a slight decrease in cold pain during the application (from $6.0 \pm 0.5$ to $5.1 \pm 0.4)$ and between the first application and the last application (from $6.7 \pm 0.4$ to $4.5 \pm 0.4$ ). CPM correlated positively with habituation of cold pain, i.e. the decline of perceived pain in the foot at the end of the experiment, $(r=+0.49, p<0.05)$ and negatively with cold pain ratings at the end of the compress application $(r=-0.45$, $p<0.05$ )

Habituation of cold pain ratings correlated with cold-induced responses in areas related to physiological CPM. In particular, like the latter, habituation was related to early cold-induced activation in rostro-medial PFC [-6 6522 ], mOFC/sgACC [-12 29 -8] and cerebellum [3 -73 -17] (FWER $p<0.05$, cluster level) and other cluster in mOFC VOI confirmed by directed search [6 $32-14]$. There was, in addition, a medulla/caudal pons cluster [ $6-40-35]$ where negative responses to sustained cold correlated with greater habituation to cold (FWER $p<0.05$, cluster level).

\section{Discussion}

The objective of our study was to better understand the neuronal mechanisms of conditioned pain modulation (CPM) using the heterotopic noxious stimulation paradigm. For this purpose, 


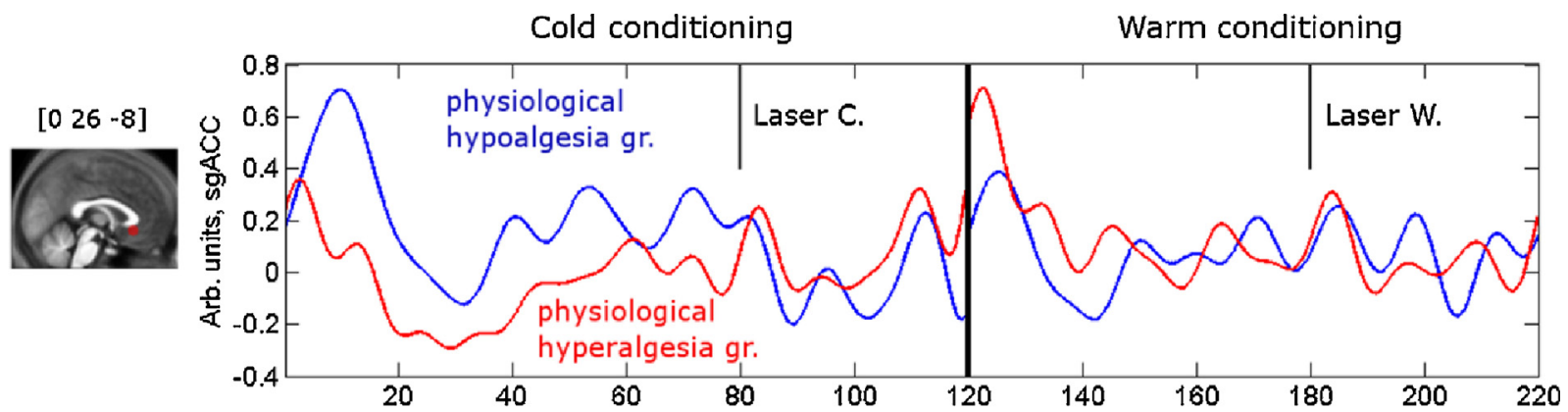

[9 44 10]
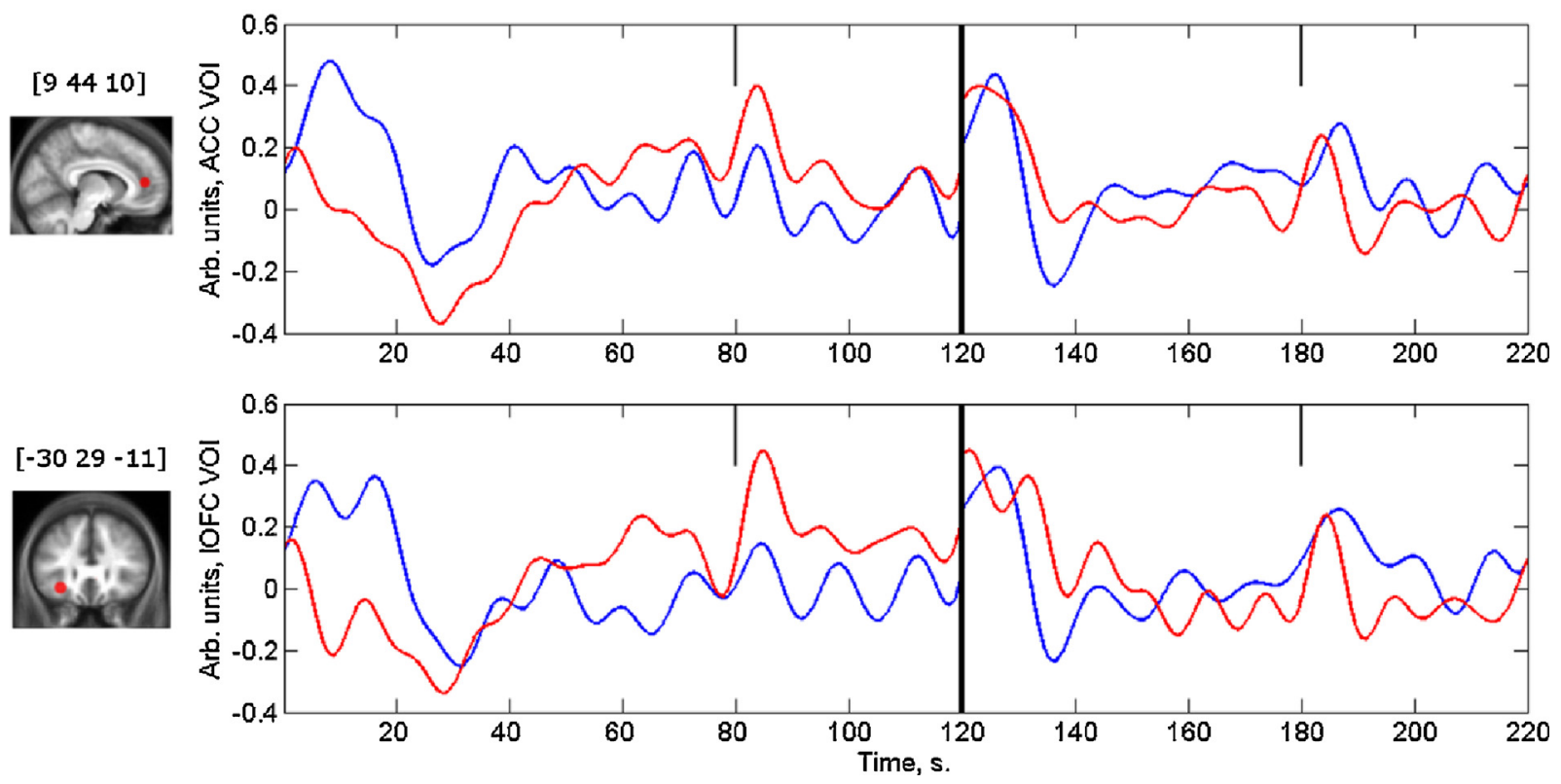

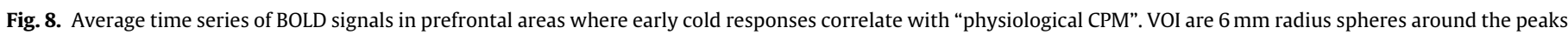

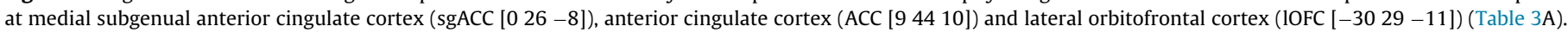

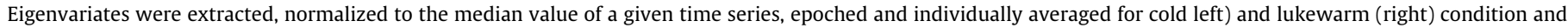

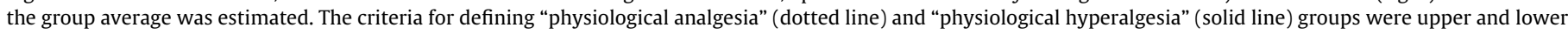

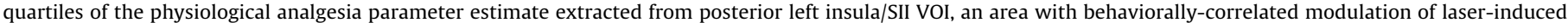
neuronal responses (see methods 2.5.2 and results 3.2.5).

we searched whether individual differences between conditioned modulation of behavioral and cerebral responses to the test heat pain were related to the cerebral responses induced by the cold conditioning stimulation.

\subsection{Behavioral pain ratings}

On average, over the 10 consecutive trials, there was no significant decrease in laser pain ratings during the conditioning cold stimulation. Facilitatory CPM (i.e. hyperalgesia) was observed in other studies, though overall in a smaller proportion of subjects. In pre-operative pain-free patients, facilitatory CPM predicts subsequent post-surgery chronic pain [40] and higher analgesic consumption [41]. The likelihood to have facilitatory CPM of a heat test stimulus by tourniquet ischemic noxious conditioning was higher in subjects with low 5-HTT expression [42]. In our study, only $29 \%$ of subjects had pain reduction, while $29 \%$ had no change and $42 \%$ increased laser pain, clearly demonstrating inter-individual differences. This contrasts with other CPM studies $[15,16]$ and could have several non-mutually exclusive explanations.

The degree of CPM varies between studies and depends on the study design. For instance, CPM was markedly greater (50\%) in Piché et al. [15] than in Sprenger et al. (20\%) [16]. In our study, the conditioning cold stimulation was applied repeatedly compared to a single counterstimulation in the two previous studies $[15,16]$. Individual differences in habituation to repeated noxious stimuli may thus play a role in our paradigm, the more so that we found a positive correlation between habituation of cold-induced pain across sessions and cold-induced laser pain reduction. Test pain produced by the trains of electric shocks like in Piché et al.'s protocol may be more amenable to a behavioral CPM effect than pain induced by a thermal stimulus with slower onset and offset slopes used in Sprenger et al.'s [16] and in our study. Also, our subjects rated the test stimulus as less painful (3.8/10 NRS) compared to those of the above-mentioned studies. This may have contributed to the lack of conditioned hypoalgesia in some subjects, as the CPM effect can be proportional to the test pain intensity [43]. However, it is known that moderately painful test stimuli [15,44] (about 40-50/100 VAS), and even only slightly painful ones [31] are sufficient to obtain reliable CPM.

Other methodological issues are discussed in Supplementary Material 4.

Besides methodological aspects related to the experimental design, psychobehavioral factors might contribute to the large interindividual variability we found for CPM.

Among them, a priori expectation is well known to strongly correlate with drug-induced analgesia [45] and pain modulation $[32,33,44]$. In the case of pharmacological opioid analgesia, 
expectations of increased pain abolished the effect of analgesia, which was associated with increased anxiety [45]. Expectation of hyperalgesia cannot only block inhibitory CPM, but turn it into facilitatory CPM. Under noxious cold conditioning in females, expectation of analgesia led to inhibitory CPM of single test stimuli, expectation of hyperalgeasia to facilitatory CPM, while no information was associated with intermediate responses [33]. Stronger analgesia expectation and reduced stress during noxious cold conditioning were linked to greater inhibitory CPM [32]. Although we kept our subjects blind about the direction of expected pain intensity changes induced by the cold applications, we cannot exclude that expectation played a role in some of them. Uncertainty about upcoming pain intensity also has a specific and potent hyperalgesic effect [46]. Anxiety is known to partially mediate the effect of expectation on the direction of CPM [44]. Our finding that anxiety was negatively related with behavioral CPM supports a role of psychological modulators.

\subsection{Cerebral responses to the conditioning cold stimulation}

We found highly significant (voxel level FWER $p<0.05$ ) nonspecific activations at onset and offset of both cold and lukewarm stimulations in many areas belonging to the so-called "pain matrix". The maximum of this non-specific response was in left SI, which is consistent with somatosensory responses to the alternating sensory stimulation of the right foot.

By contrast, when early responses to cold were contrasted against early responses to lukewarm application to detect painspecific activation, a cluster comprising mainly bilateral precuneus was significantly activated but not "pain matrix" areas such as ACC and insula. The precuneus is known to respond to multimodal salient stimuli [47].

We found no significant activation in most areas of the "pain matrix" during the subsequent sustained phase of cold application, with the notable exception of posterior insula/SII. The latter activation is consistent with a central role for the operculo-insular cortex in specific pain processing and coding of pain intensity [48-53]. Although our study was not specifically designed to address this question, its results favor nonetheless the concept that the "pain matrix" is mostly a "salience matrix" of areas that process salient multimodal sensory inputs [54] and that the posterior insula may be more pain-specific [50,53].

During the sustained phase of cold application, we found deactivation in medial OFC. This area is known to be activated by valuation of a reward outcome [55] and we speculate that its deactivation could be related to the negative affective response due to the sustained noxious stimulation. The observed clusters of sustained BOLD response in the white matter are discussed in Supplementary Material 5.

\subsection{Cerebral responses to the laser test stimulus and their conditioning by cold stimulation}

Laser pain-induced activations were significant in various areas of the "pain matrix" in line with a number of prior studies $[47,56,57]$. This indicates that the intensity of the laser stimuli was sufficient to induce cerebral responses typically reported after noxious stimulation.

Similar to the behavioral laser pain ratings (see Section 4.1), the laser-induced BOLD responses did not differ on average between cold and lukewarm conditioning. The inter-individual variation in CPM, however, that ranged from reduction to increase in pain was correlated with the modulation of the BOLD response. Behavioral cold-induced hypoalgesia was associated with the suppression of laser-induced responses in posterior insula and SII contralateral to the cold stimulation. Like sustained cold-induced
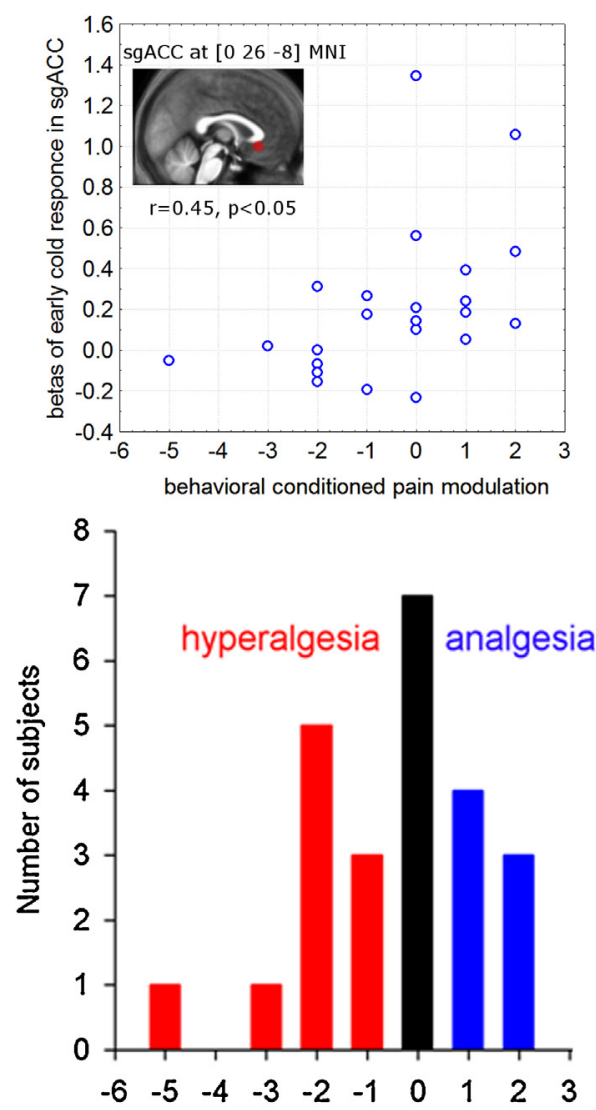

Fig. 9. Relationship between activation of sgACC and behavioral conditioned pain modulation. Eigenvariates of beta images for only early cold response were extracted from a sphere of $6 \mathrm{~mm}$ radius around the peak of early cold vs early warm contrast significantly correlated to "physiological conditioned pain modulation" (the eigenvariates of the laser warm vs laser cold contrast correlated to behavioral conditioned pain modulation) (Table $3 \mathrm{~A}$ ). The scatter pot is only for illustration purposes.

activation, the physiological CPM thus involved the posterior insula, supporting again its critical role in pain as well as CPM processing $[50,53]$.

\subsection{Correlation of cold-induced cerebral responses with physiological CPM}

In medial and lateral OFC, ACC, rostral and caudal lateral PFC, the early cold-induced BOLD responses were directly related to subsequent CPM (see Figs. 8 and 9). These findings are in agreement with other studies, where CPM was associated with activity evoked by the cold pain stimulus in MPFC, lateral OFC $[15,26]$ and rostral ACC [16]. By contrast, BOLD activation during the later phase of cold stimulation was less predictive of physiological CPM, as the correlation was significant only in rostro-lateral PFC.

The correlation between early cold-induced PFC responses and subsequent physiological CPM could be due to the fact that the conditioning stimulus is able to strengthen connectivity between cortical sources of descending analgesia and their targets in subcortical structures [58]. For instance, increased connectivity of subgenual ACC with midbrain and amygdala was correlated with CPM [16].

We also found an unexpected correlation between physiological CPM and deactivation in lateral OFC, ACC, lateral rostral and caudal PFC areas during sustained cold application, which was not reported in others studies $[15,16]$. This may be due to the different experimental design of our study, but differences in expectation 
or so-called "off-set analgesia" could be alternative explanations. In a model of visceral pain, expectation-mediated placebo analgesia was associated with fMRI deactivation in the dorsolateral PFC [59]. Negative BOLD responses in ventro-medial PFC/OFC were also recorded during large reductions of pain rating induced by a slight decrease of a noxious stimulation, i.e. off-set analgesia [8]. This paradigm could be relevant for our study where there was habituation of cold pain ratings between the 1st and last applications, and hence a decrease in perceived pain.

\subsection{Correlations with cold pain habituation}

Habituation of cold pain perception correlated positively with behavioral CPM, with early cold-induced lateral OFC activation that is also related to physiological CPM, and with sustained coldinduced deactivation in pons/cerebellum. Habituation of pain over several days was found associated with subgenual ACC activation [60]. Habituation thus likely involves central neuronal networks that it shares at least partially with CPM. Diffuse noxious inhibitory control, non-noxious inhibitory control and habituation are all part of endogenous analgesia and thought to be related to each other [43].

To conclude, our study confirms that sustained noxious cold stimulation chiefly activates posterior insula/SII. Activation in other areas of the so-called "pain matrix" appears to be merely determined by saliency and novelty rather than by the noxious character of the stimulus. We find great inter-individual differences in CMP that ranges from decreases to increases of the test laser-heat pain. Larger prefrontal positive BOLD responses to early cold stimulation seem to predict subsequent conditioned analgesia. By contrast, in adjacent prefrontal cortices conditioned analgesia is associated with deactivation during the sustained conditioning cold stimulation. We show that CPM is negatively correlated with trait anxiety, but positively with habituation of cold pain. The individual differences in prefrontal cortex activity and CPM need to be considered in future studies of diseased subjects, including migraineurs.

\section{Acknowledgements}

This study was supported by the research convention 3.4.650.09 from the National Fund for Scientific Research-Belgium to J.S., and by a research grant from the $\mathrm{CHU}$ of Clermont-Ferrand-France to R.D. and J.S. We are grateful to Drs André Luxen, Eric Salmon and Pierre Maquet for organizational and to Christian Degueldre for technical assistance.

The authors declare no conflicts of interest.

\section{Appendix A. Supplementary data}

Supplementary data associated with this article can be found, in the online version, at http://dx.doi.org/10.1016/j.bbr.2014.11.028.

\section{References}

[1] Mayer DJ, Liebeskind JC. Pain reduction by focal electrical stimulation of the brain: an anatomical and behavioral analysis. Brain Res 1974;68:73-93.

[2] Le Bars D, Chitour D, Kraus E, Clot AM, Dickenson AH, Besson JM. The effect of systemic morphine upon diffuse noxious inhibitory controls (DNIC) in the rat: evidence for a lifting of certain descending inhibitory controls of dorsal horn convergent neurones. Brain Res 1981;215:257-74.

[3] Gear RW, Aley KO, Levine JD. Pain-induced analgesia mediated by mesolimbic reward circuits. J Neurosci 1999;19:7175-81.

[4] Levine JD, Gordon NC, Fields HL. The mechanism of placebo analgesia. Lancet 1978;2:654-7.

[5] Valet M, Sprenger T, Boecker H, Willoch F, Rummeny E, Conrad B, et al. Distraction modulates connectivity of the cingulo-frontal cortex and the midbrain during pain-an fMRI analysis. Pain 2004;109:399-408.
[6] Freund W, Klug R, Weber F, Stuber G, Schmitz B, Wunderlich AP. Perception and suppression of thermally induced pain: a fMRI study. Somatosens Mot Res 2009;26:1-10.

[7] Yilmaz P, Diers M, Diener S, Rance M, Wessa M, Flor H. Brain correlates of stress-induced analgesia. Pain 2010;151:522-9.

[8] Yelle MD, Oshiro Y, Kraft RA, Coghill RC. Temporal filtering of nociceptive information by dynamic activation of endogenous pain modulatory systems. J Neurosci 2009;29:10264-71.

[9] Leknes S, Berna C, Lee MC, Snyder GD, Biele G, Tracey I. The importance of context: when relative relief renders pain pleasant. Pain 2013;154:402-10.

[10] Pud D, Granovsky Y, Yarnitsky D. The methodology of experimentally induced diffuse noxious inhibitory control (DNIC)-like effect in humans. Pain 2009;144:16-9.

[11] Yarnitsky D, Arendt-Nielsen L, Bouhassira D, Edwards RR, Fillingim RB, Granot M, et al. Recommendations on terminology and practice of psychophysical DNIC testing. Eur J Pain 2010;14:12.

[12] Carstens E, Yokota T, Zimmermann M. Inhibition of spinal neuronal responses to noxious skin heating by stimulation of mesencephalic periaqueductal gray in the cat. J Neurophysiol 1979;42:558-68.

[13] Villanueva L, Le Bars D. The activation of bulbo-spinal controls by peripheral nociceptive inputs: diffuse noxious inhibitory controls. Biol Res 1995;28:113-25.

[14] Sluka KA, Deacon M, Stibal A, Strissel S, Terpstra A. Spinal blockade of opioid receptors prevents the analgesia produced by TENS in arthritic rats. J Pharmacol Exp Ther 1999;289:840-6.

[15] Piche M, Arsenault M, Rainville P. Cerebral and cerebrospinal processes underlying counterirritation analgesia. J Neurosci 2009;29:14236-46.

[16] Sprenger C, Bingel U, Buchel C. Treating pain with pain: supraspinal mechanisms of endogenous analgesia elicited by heterotopic noxious conditioning stimulation. Pain 2011;152:428-39.

[17] van Wijk G, Veldhuijzen DS. Perspective on diffuse noxious inhibitory controls as a model of endogenous pain modulation in clinical pain syndromes. J Pain 2010;11:408-19.

[18] Pielsticker A, Haag G, Zaudig M, Lautenbacher S. Impairment of pain inhibition in chronic tension-type headache. Pain 2005;118:215-23.

[19] Sandrini G, Rossi P, Milanov I, Serrao M, Cecchini AP, Nappi G. Abnormal modulatory influence of diffuse noxious inhibitory controls in migraine and chronic tension-type headache patients. Cephalalgia 2006;26:782-9.

[20] de Tommaso M, Difruscolo O, Sardaro M, Libro G, Pecoraro C, Serpino $C$, et al. Effects of remote cutaneous pain on trigeminal laserevoked potentials in migraine patients. J Headache Pain 2007;8: 167-74.

[21] Staud R, Robinson ME, Vierck Jr CJ, Price DD. Diffuse noxious inhibitory controls (DNIC) attenuate temporal summation of second pain in normal males but not in normal females or fibromyalgia patients. Pain 2003;101:167-74.

[22] Normand E, Potvin S, Gaumond I, Cloutier G, Corbin JF, Marchand S. Pain inhibition is deficient in chronic widespread pain but normal in major depressive disorder. J Clin Psychiatry 2010; 72:219-24.

[23] Wilder-Smith CH, Schindler D, Lovblad K, Redmond SM, Nirkko A. Brain functional magnetic resonance imaging of rectal pain and activation of endogenous inhibitory mechanisms in irritable bowel syndrome patient subgroups and healthy controls. Gut 2004;53:1595-601.

[24] Kosek E, Ordeberg G. Lack of pressure pain modulation by heterotopic noxious conditioning stimulation in patients with painful osteoarthritis before, but not following, surgical pain relief. Pain 2000;88:69-78.

[25] Wilder-Smith OH, Schreyer T, Scheffer GJ, Arendt-Nielsen L. Patients with chronic pain after abdominal surgery show less preoperative endogenous pain inhibition and more postoperative hyperalgesia: a pilot study. J Pain Palliat Care Pharmacother 2010;24:119-28.

[26] Moont R, Crispel Y, Lev R, Pud D, Yarnitsky D. Temporal changes in cortical activation during conditioned pain modulation (CPM), a LORETA study. Pain 2011;152:1469-77.

[27] Song GH, Venkatraman V, Ho KY, Chee MW, Yeoh KG, Wilder-Smith CH. Cortical effects of anticipation and endogenous modulation of visceral pain assessed by functional brain MRI in irritable bowel syndrome patients and healthy controls. Pain 2006;126:79-90.

[28] Peyron R, Laurent B, Garcia-Larrea L. Functional imaging of brain responses to pain. A review and meta-analysis. Neurophysiol Clin 2000;30: 263-88.

[29] Harper RM, Macey PM, Henderson LA, Woo MA, Macey KE, Frysinger RC, et al. fMRI responses to cold pressor challenges in control and obstructive sleep apnea subjects. J Appl Physiol 2003;94:1583-95.

[30] Macey PM, Macey KE, Woo MA, Keens TG, Harper RM. Aberrant neural responses to cold pressor challenges in congenital central hypoventilation syndrome. Pediatr Res 2005;57:500-9.

[31] Plaghki L, Delisle D, Godfraind JM. Heterotopic nociceptive conditioning stimuli and mental task modulate differently the perception and physiological correlates of short $\mathrm{CO}_{2}$ laser stimuli. Pain 1994;57:181-92.

[32] Bjorkedal E, Flaten MA. Expectations of increased and decreased pain explain the effect of conditioned pain modulation in females. J Pain Res 2012:5:289-300.

[33] Goffaux P, Redmond WJ, Rainville P, Marchand S. Descending analgesia-when the spine echoes what the brain expects. Pain 2007;130:137-43.

[34] Spielberger CD, Goruch RL, Lushene PR, Vagg PR, Jacobs GA. Manual for the state-trait anxiety inventory (form Y). Palo Alto, CA: Consulting Psychologists Press; 1983, 36 p. 
[35] Spielberger CD, Bruchon-Schweitzer ML, Paulhan I. Manuel pour l'inventaire d'Anxiété Trait-État (Forme Y). Paris, France: Les Editions du Centre de Psychologie Appliqée; 1993, 68 p.

[36] Deichmann R, Schwarzbauer C, Turner R. Optimisation of the 3D MDEFT sequence for anatomical brain imaging: technical implications at 1.5 and $3 \mathrm{~T}$. Neuroimage 2004;21:757-67.

[37] Andersson JL, Hutton C, Ashburner J, Turner R, Friston K. Modeling geometric deformations in EPI time series. Neuroimage 2001;13:903-19.

[38] Hutton C, Bork A, Josephs O, Deichmann R, Ashburner J, Turner R. Image distortion correction in fMRI: a quantitative evaluation. Neuroimage 2002;16:217-40.

[39] Ashburner J, Friston KJ. Unified segmentation. Neuroimage 2005;26:839-51.

40] Yarnitsky D, Crispel Y, Eisenberg E, Granovsky Y, Ben-Nun A, Sprecher E, et al. Prediction of chronic post-operative pain: pre-operative DNIC testing identifies patients at risk. Pain 2008;138:22-8,. Epub 2008 Jan 8.

[41] Grosen K, Vase L, Pilegaard HK, Pfeiffer-Jensen M, Drewes AM. Conditioned pain modulation and situational pain catastrophizing as preoperative predictors of pain following chest wall surgery: a prospective observational cohort study. PLoS One 2014;9:2014

[42] Lindstedt F, Berrebi J, Greayer E, Lonsdorf TB, Schalling M, Ingvar M, et al. Conditioned pain modulation is associated with common polymorphisms in the serotonin transporter gene. PLoS One 2011;6:0018252.

[43] Treister R, Eisenberg E, Gershon E, Haddad M, Pud D. Factors affecting-and relationships between-different modes of endogenous pain modulation in healthy volunteers. Eur J Pain 2010;14:608-14.

[44] Cormier S, Piche M, Rainville P. Expectations modulate heterotopic noxious counter-stimulation analgesia. J Pain 2013;14:114-25.

[45] Bingel U, Wanigasekera V, Wiech K, Ni Mhuircheartaigh R, Lee MC, Ploner $M$, et al. The effect of treatment expectation on drug efficacy: imaging the analgesic benefit of the opioid remifentanil. Sci Transl Med 2011;3, 70 ra14.

[46] Yoshida W, Seymour B, Koltzenburg M, Dolan RJ. Uncertainty increases pain: evidence for a novel mechanism of pain modulation involving the periaqueductal gray. J Neurosci 2013;33:5638-46.

[47] Mouraux A, Diukova A, Lee MC, Wise RG, Iannetti GD. A multisensory investigation of the functional significance of the pain matrix. Neuroimage 2011;54:2237-49.
[48] Ostrowsky K, Magnin M, Ryvlin P, Isnard J, Guenot M, Mauguiere F. Representation of pain and somatic sensation in the human insula: a study of responses to direct electrical cortical stimulation. Cereb Cortex 2002;12:376-85.

[49] Brooks JC, Tracey I. The insula: a multidimensional integration site for pain. Pain 2007; 128:1-2.

[50] Garcia-Larrea L, Perchet C, Creac'h C, Convers P, Peyron R, Laurent B, et al Operculo-insular pain (parasylvian pain): a distinct central pain syndrome. Brain 2010;133:2528-39.

[51] Isnard J, Magnin M, Jung J, Mauguiere F, Garcia-Larrea L. Does the insula tel our brain that we are in pain. Pain 2011;152:946-51.

[52] Fairhurst M, Fairhurst K, Berna C, Tracey I. An fMRI study exploring the overlap and differences between neural representations of physical and recalled pain. PLoS One 2012; 7:e48711.

[53] Pomares FB, Faillenot I, Barral FG, Peyron R. The 'where' and the 'when' of the BOLD response to pain in the insular cortex. Discussion on amplitudes and latencies. Neuroimage 2013;64:466-75.

[54] Iannetti GD, Mouraux A. From the neuromatrix to the pain matrix (and back) Exp Brain Res 2010;205:1-12

[55] O’Doherty J, Kringelbach ML, Rolls ET, Hornak J, Andrews C. Abstract reward and punishment representations in the human orbitofrontal cortex. Nat Neurosci 2001;4:95-102.

[56] Mobascher A, Brinkmeyer J, Warbrick T, Musso F, Wittsack HJ, Stoerme $\mathrm{R}$, et al. Fluctuations in electrodermal activity reveal variations in single trial brain responses to painful laser stimuli-a fMRI/EEG study. Neuroimage 2009;44:1081-92.

[57] Watson A, El-Deredy W, Iannetti GD, Lloyd D, Tracey I, Vogt BA, et al. Placebo conditioning and placebo analgesia modulate a common brain network during pain anticipation and perception. Pain 2009;145:24-30.

[58] Kong J, Jensen K, Loiotile R, Cheetham A, Wey HY, Tan Y, et al. Functional connectivity of the frontoparietal network predicts cognitive modulation of pain. Pain 2013;154:459-67.

[59] Elsenbruch S, Kotsis V, Benson S, Rosenberger C, Reidick D, Schedlowski M, et al. Neural mechanisms mediating the effects of expectation in visceral placebo analgesia: an fMRI study in healthy placebo responders and nonresponders. Pain 2012;153:382-90.

[60] Bingel U, Schoell E, Herken W, Buchel C, May A. Habituation to painful stimulation involves the antinociceptive system. Pain 2007;131:21-30. 